\title{
Synthesis of $\mathrm{BiSl} / \mathrm{Ag}_{2} \mathrm{CO}_{3}$ Composite Material for Photocatalytic Degradation of Rhodamine $B$ under Visible Light
}

\section{Rui Zhang}

Southwest Petroleum University

ziyin chen ( $\nabla 760374659 @ q q . c o m$ )

Southwest Petroleum University

Chen Zhao

Southwest Petroleum University

Kunlin Zeng

Southwest Petroleum University

Lu Cai

Southwest Petroleum University

Junrong Yu

Southwest Petroleum University

Ze Yang

Southwest Petroleum University

Jiacheng Jiang

Southwest Petroleum University

\section{Research Article}

Keywords: BiSI/Ag2CO3, RhB, Photocatalysts

Posted Date: September 17th, 2021

DOl: https://doi.org/10.21203/rs.3.rs-883480/v1

License: (a) This work is licensed under a Creative Commons Attribution 4.0 International License.

Read Full License 


\section{Abstract}

A novel binary $\mathrm{BiSl} / \mathrm{Ag}_{2} \mathrm{CO}_{3}$ photocatalyst with excellent visible light-driven photocatalytic performance was prepared. The products were characterized by X-ray powder diffraction (XRD), scanning electron microscopy (SEM), ultraviolet-visible diffuse reflectance spectroscopy (UV-Vis DRS) and electrochemical impedance spectroscopy (EIS). The photocatalytic activity of the samples were evaluated by photocatalytic degradation of rhodamine $\mathrm{B}(\mathrm{RhB})$ under the irradiation of visible light. The results showed that the $\mathrm{BiSI}$ improves the photocatalytic activity of $\mathrm{BiSI} / \mathrm{Ag}_{2} \mathrm{CO}_{3}$. Moreover, when the mass ratio of BiSI in $\mathrm{BiSl} / \mathrm{Ag}_{2} \mathrm{CO}_{3}$ composites was $40 \%$, the as-prepared $\mathrm{BiSl} / \mathrm{Ag}_{2} \mathrm{CO}_{3}$ composite exhibited the best photocatalytic activity for degrading RhB. Finally, the possible mechanism for photodegradation over the $\mathrm{BiSI} / \mathrm{Ag}_{2} \mathrm{CO}_{3}$ composites is also proposed.

\section{Introduction}

In recent years, semiconductor photocatalysis technology has attracted great attention in the field of environmental protection due to its obvious advantages of low economic cost, no secondary pollution to degrade the organic pollutants. Although traditional photocatalysts such as $\mathrm{TiO}_{2}$ has some advantages of good stability, nontoxicity, high activity and low cost, it still has some drawbacks, which limit its practical application ability ${ }^{[1-8]}$. Therefore, in order to degrade pollutants more effectively, it is more important to apply a new type of visible light-driven photocatalyst with high activity and stability.

At present, Ag-based photocatalytic materials, including $\mathrm{AgCl}^{[9]}, \mathrm{Ag}_{2} \mathrm{O}^{[10]}, \mathrm{AgVO}_{3}{ }^{[11]}, \mathrm{Ag}_{3} \mathrm{PO}_{4}{ }^{[12]}, \mathrm{Ag}_{2} \mathrm{CO}_{3}{ }^{[13-}$ ${ }^{14]}, \mathrm{Ag}_{2} \mathrm{CrO}_{4}{ }^{[15]}$ etc., exhibit excellent photocatalytic performance for organic pollutant degradation. Among them, the band gap energy of $\mathrm{Ag}_{2} \mathrm{CO}_{3}$ is only $2.1 \otimes 2.4 \mathrm{eV}$, which is a typical narrow band gap semiconductor with high photocatalytic degradation ability. However, all Ag-based photocatalysts, including $\mathrm{Ag}_{2} \mathrm{CO}_{3}$, have strong photocorrosion and are prone to severe inactivation during the catalysis process $^{[16-18]}$. What's more, the exhibition of electron-hole pairs recombination in high rate can directly lower the photocatalytic activity ${ }^{[19-23]}$. Therefore, the photocatalytic performance of a single $\mathrm{Ag}_{2} \mathrm{CO}_{3}$ semiconductor photocatalyst is limited in practical applications. Previous reports indicate that $\mathrm{Ag}_{2} \mathrm{CO}_{3}$ can effectively recombine with other semiconductors, forming a heterojunction structure through appropriate conduction band( $\mathrm{CB})$ and valence band(VB) positions, promoting the separation of photogenerated electron-hole pairs, and improving the catalytic performance of semiconductor materials ${ }^{\text {[24-25] }}$. Hence, it is possible that the composite photocatalyst synthesized by $\mathrm{BiSI}$ and $\mathrm{Ag}_{2} \mathrm{CO}_{3}$ might have better photocatalytic activity than pure BiSI or $\mathrm{Ag}_{2} \mathrm{CO}_{3}$. However, there are no work focusing on the preparation and photocatalytic performance of $\mathrm{BiSl} / \mathrm{Ag}_{2} \mathrm{CO}_{3}$ composite materials.

Herein, a simple method was used to synthesize $\mathrm{BiSI} / \mathrm{Ag}_{2} \mathrm{CO}_{3}$ composites. The photocatalytic properties of the as-prepared products were studied via the degradation of Rhodamine $B(R h B)$ under visible light illumination. The $\mathrm{BiSI} / \mathrm{Ag}_{2} \mathrm{CO}_{3}$ composites showed superior photocatalytic performance to $\mathrm{BiSI}$ or 
$\mathrm{Ag}_{2} \mathrm{CO}_{3}$. The $\mathrm{BiSI}$ amounts in the $\mathrm{BiSl} / \mathrm{Ag}_{2} \mathrm{CO}_{3}$ composites have a significant influence on the corresponding photocatalytic properties, the photocatalytic mechanism was investigated.

\section{Materials And Methods}

\subsection{Materials}

All the chemicals used for the synthesis are of analytical grade and are used without further processing. $\mathrm{Bi}(\mathrm{NO})_{3} \cdot 5 \mathrm{H}_{2} \mathrm{O}, \mathrm{CH}_{3} \mathrm{CSNH}_{2}, \mathrm{Nal}, \mathrm{CH}_{3} \mathrm{COOH}, \mathrm{AgNO}_{3}$, and $\mathrm{Na}_{2} \mathrm{CO}_{3}$ was purchased from Kelon (Chengdu).

\subsection{Preparation of catalyst}

\subsubsection{Preparation of BiSI}

At room temperature, add $0.728 \mathrm{~g} \mathrm{Bi}(\mathrm{NO})_{3} \cdot 5 \mathrm{H}_{2} \mathrm{O}$ to $30 \mathrm{~mL} \mathrm{CH} \mathrm{CHOH}_{3} \mathrm{COnd}$ stir until completely dissolved. Then, $0.113 \mathrm{~g} \mathrm{CH}_{3} \mathrm{CSNH}_{2}$ was added and stirred until the mixed solution became milky white for 15 minutes. $0.374 \mathrm{~g} \mathrm{Nal}$ was added after 15 minutes, and after stirring for 3 hours, the mixed solution was heated at $180^{\circ} \mathrm{C}$ for 10 hours, and finally centrifuged and dried at $60^{\circ} \mathrm{C}$ for several hours.

\subsubsection{Preparation of $\mathrm{BiSI} / \mathrm{Ag}_{2} \mathrm{CO}_{3}$}

Add $0.1987 \mathrm{~g} \mathrm{BiSI}$ to $30 \mathrm{~mL}$ of deionized water at room temperature, ultrasonic for half an hour to make it uniformly dispersed, then add $0.616 \mathrm{~g} \mathrm{AgNO}_{3}$ and stir for $1.5 \mathrm{~h}$. After stirring for $1.5 \mathrm{~h}, 0.191 \mathrm{~g}$ of $\mathrm{Na}_{2} \mathrm{CO}_{3}$ dissolved in $30 \mathrm{~mL}$ of deionized water was added dropwise. And stirred for $4 \mathrm{~h}$. After centrifuging the obtained precipitate, it was washed several times with deionized water and ethanol, and dried at $60^{\circ} \mathrm{C}$ for a period of time. The whole reaction was carried out under dark conditions.

\subsection{Characterization}

The crystal plane of the catalyst sample was detected by X-ray powder diffraction (XRD), the surface morphology of the catalyst was observed by scanning electron microscope (SEM), and the chemical composition of the catalyst was passed X-ray photoelectron microscopy (XPS). The catalyst ultraviolet visible diffuse reflectance spectroscopy (UV-vis DRS) was used to obtain the absorption spectra of different samples and subsequent band gap calculation by using Kubelka-Munk function. The separation and transfer efficiency of photo-generated carriers of each catalyst was tested by electrochemical impedance spectroscopy (EIS).

\subsection{Photocatalytic experiment}

Using an incandescent lamp as a light source, the degradation effect of the photocatalyst was tested by degrading $20 \mathrm{mg} / \mathrm{L}$ of rhodamine. $50 \mathrm{mg}$ of the catalyst was dispersed into $50 \mathrm{~mL}$ of aqueous solution containing RhB and stirred in the dark for 30 minutes to make the catalyst and the mixed solution reach 
an adsorption-desorption equilibrium. After the light is irradiated, the concentration of RhB in the solution is measured by a spectrophotometer. The degradation efficiency of RhB can be calculated by the following formula:

$$
\eta=\frac{C_{0}-C_{t}}{C_{0}}
$$

where $C_{0}$ is the initial concentration. and $C_{t}$ is the concentration at time $t$.

\subsection{Photo-electrochemical measurements}

Photo-electrochemistry uses a standard three-electrode model to measure on an electrochemical workstation, using calomel electrode as the reference electrode, platinum wire as the counter electrode, and conductive glass coated with photocatalyst as the working electrode. The three-electrode system works in $0.5 \mathrm{~mol} / \mathrm{L} \mathrm{Na}_{2} \mathrm{SO}_{4}$ solution. The preparation of the working electrode is as follows: Take $10 \mathrm{mg}$ of photocatalyst and place it in a beaker, add $2 \mathrm{~mL}$ of ethanol and then add $100 \mathrm{uL}$ of naphthol, place the beaker under ultrasound for 30 minutes, take the ultrasound mixture and coat it on a conductive glass with an area of $1 \mathrm{~cm} \times 4 \mathrm{~cm}$. Dry in an oven at $100^{\circ} \mathrm{C}$ for 6 hours.

\section{Results And Discussion}

\subsection{Characterization}

\subsubsection{XRD}

The crystal structures of $\mathrm{BiSI}, \mathrm{Ag}_{2} \mathrm{CO}_{3}$, and $\mathrm{BiSI} / \mathrm{Ag}_{2} \mathrm{CO}_{3}$ composites were analyzed based on the XRD patterns. Seen from Figure 1, the three primary diffraction summits of BiSI are situated at $20.8^{\circ}, 29.6^{\circ}$, and $32.7^{\circ}$ in agreement with JCPDS No.43-0652, which matches with (120), (121), and (310) lattice planes of orthorhombic $\mathrm{BiSl}$. The pure $\mathrm{Ag}_{2} \mathrm{CO}_{3}$ have many diffraction peaks, and obvious characteristic diffraction peaks appear at $18.5^{\circ}, 20.5^{\circ}, 32.6^{\circ}, 33.6^{\circ}, 37.1^{\circ}$ and $39.6^{\circ}$, corresponding to (020), (110), (-101), (-130), (200) and, (031) planes of $\mathrm{Ag}_{2} \mathrm{CO}_{3}$, respectively, indexed to the $\mathrm{Ag}_{2} \mathrm{CO}_{3}$ (JCPDS No.26-

0339). The diffraction peak was sharp and has no impurity peak, indicating that the prepared $\mathrm{Ag}_{2} \mathrm{CO}_{3}$ has good crystallinity and high purity. As seen from the $\mathrm{BiSI} / \mathrm{Ag}_{2} \mathrm{CO}_{3}$, the diffraction peak of the synthesized $\mathrm{BiSI} / \mathrm{Ag}_{2} \mathrm{CO}_{3}$ composite photocatalyst can correspond to the diffraction peak of pure $\mathrm{BiSI}$ and the diffraction peak of pure $\mathrm{Ag}_{2} \mathrm{CO}_{3}$, which indicates that $\mathrm{BiSI}$ and $\mathrm{Ag}_{2} \mathrm{CO}_{3}$ have been successfully coupled.

\subsubsection{SEM}

The microstructure of the prepared material was examined by SEM, and the result is shown in Figure 2. As shown in Fig. $3 a$, BiSI presents an irregular sheet structure. Figure $2 \mathrm{~b}$ shows $\mathrm{Ag}_{2} \mathrm{CO}_{3}$ monomer, its 
structure presents an irregular short rod structure and relatively smooth surface. Moreover, it can be observed from Fig. $2 \mathrm{c}$ that $\mathrm{BiSI}$ and $\mathrm{Ag}_{2} \mathrm{CO}_{3}$ are tightly combined and this structure facilitates the migration and separation of photo-generated electron-hole pairs.

\subsubsection{Electronic structure analysis of samples}

UV- vis DRS was used to determine the optical absorption of $\mathrm{BiSI}, \mathrm{Ag}_{2} \mathrm{CO}_{3}$ and $\mathrm{BiSl} / \mathrm{Ag}_{2} \mathrm{CO}_{3}$ samples at different wavelengths (200-800 nm). It can be seen from Fig. 4 a that $\mathrm{BiSI}, \mathrm{Ag}_{2} \mathrm{CO}_{3}$ and $\mathrm{BiSI} / \mathrm{Ag}_{2} \mathrm{CO}_{3}$ samples all have absorption bands in the visible light region. Compared with pure $\mathrm{Ag}_{2} \mathrm{CO}_{3}$ samples, the light absorption of $\mathrm{BiSl} / \mathrm{Ag}_{2} \mathrm{CO}_{3}$ in the visible light region is significantly enhanced, and the absorption edge exhibits an obvious red-shift to longer wavelength. It means that the addition of BiSI expands the visible light response of $\mathrm{Ag}_{2} \mathrm{CO}_{3}$.

Furthermore, Fig. $4 \mathrm{a}$ and $4 \mathrm{~b}$ demonstrates the band gapvalues of $\mathrm{BiSI}$ and $\mathrm{Ag}_{2} \mathrm{CO}_{3}$, which is calculated according to the formula ${ }^{[29]}$.

$\mathrm{a} h v=\mathrm{A}\left(h v-E_{g}\right)^{\mathrm{n} / 2}$

where $a, h, v, A$ and Eg represent the absorption coefficient, Planck constant, light frequency, proportionality and band gap energy, respectively. The value of $\mathrm{n}$ is determined by the optical transition form of the photocatalytic semiconductor ( $n=1$ for the direct transition semiconductor; $n=4$ for the indirect transition semiconductor). Because $\mathrm{BiSI}$ is a direct transition semiconductor and $\mathrm{Ag}_{2} \mathrm{CO}_{3}$ is an indirect transition semiconductor, their $\mathrm{n}$ values are 1 and 4 , respectively. In Fig. $4 \mathrm{a}$ and $4 \mathrm{~b}$, the $E g$ values of pure $\mathrm{BiSI}$ and $\mathrm{Ag}_{2} \mathrm{CO}_{3}$ are $1.38 \mathrm{eV}$ and $2.56 \mathrm{eV}$, respectively.

The ability of the photocatalyst to shuttle and transport the charge carrier to the target reaction site has a direct impact on its photocatalytic activity, and this electrochemical behavior can be measured by EIS ${ }^{[30]}$. Generally, the smaller the arc radius in the spectrum, the smaller the resistance during charge transfer, which means that the efficiency of photo-generated carrier separation is higher. In Fig. 5 shows the EIS Nyquist plots of $\mathrm{Ag}_{2} \mathrm{CO}_{3}$ and $\mathrm{BiSI} / \mathrm{Ag}_{2} \mathrm{CO}_{3}$. Among all the samples, $\mathrm{BiSI} / \mathrm{Ag}_{2} \mathrm{CO}_{3}$ shows the smallest diameter, suggesting the lowest resistance for interfacial charge transfer from electrode to electrolyte molecules. This shows that the addition of $\mathrm{BiSI}$ can reduce the interfacial resistance of $\mathrm{Ag}_{2} \mathrm{CO}_{3}$ and promote the rapid separation and migration of photo-generated charges.

\subsubsection{XPS}

We carried out the XPS experiment to verify the elements contented in the photocatalyst and the chemical states of them. Figure $3 \mathrm{a}-\mathrm{g}$ shows the outcomes of $\mathrm{BiSI} / \mathrm{Ag}_{2} \mathrm{CO}_{3}$. The full survey spectrum (Fig. 3a) shows that the composite is composed of $\mathrm{Ag}, \mathrm{C}, \mathrm{O}, \mathrm{Bi}, \mathrm{S}$ and I elements without other impurity elements. Fig. $3 \mathrm{~b}$ shows the high-resolution XPS spectrum for the $\mathrm{Ag} 3 \mathrm{~d}$ region. The peaks located at 367.85 and $373.86 \mathrm{eV}$ are assigned to $\mathrm{Ag} 3 \mathrm{~d}_{5 / 2}$ and $\mathrm{Ag} 3 \mathrm{~d}_{3 / 2}$, respectively, which indicating the existence of $\mathrm{Ag}^{+}$in the sample ${ }^{[26]}$. Fig. $3 \mathrm{c}$ shows that the high-resolution XPS spectrum of the $C 1$ s region shows binding energy 
peak at $284.44 \mathrm{eV}$ corresponded to the $\mathrm{C}$ elements of $\mathrm{Ag}_{2} \mathrm{CO}_{3}{ }^{[27]}$. In Fig. 3d, the low binding energy component located at $530.39 \mathrm{eV}$ was attributed to the lattice oxygen ions of $\mathrm{Ag}_{2} \mathrm{CO}_{3}$. Fig. 3e shows that the peaks of $\mathrm{Bi} 3 \mathrm{~d}$ are observed at 163.81 and $158.50 \mathrm{eV}$, ascribed to $\mathrm{Bi}^{3+}$ of $\mathrm{BiSI}^{[28]}$. The XPS spectrum in Fig. $3 f$ shows peaks located at 630.74 and $619.25 \mathrm{eV}$, which correspond to $\mathrm{I}^{-} 3 \mathrm{~d}_{3 / 2}$ and $\mathrm{I}^{-} 3 \mathrm{~d}_{5 / 2}$. As shown in Fig. $3 g$, the binding energies of $S 2 p_{3 / 2}$ and $S 2 p_{1 / 2}$ peaks in BiSI are located at 158.53 and $163.80 \mathrm{eV}$, suggesting that $\mathrm{S}$ element exists as $\mathrm{S}^{2-}$. XPS verified that the $\mathrm{BiSI} / \mathrm{Ag}_{2} \mathrm{CO}_{3}$ composite has been successfully prepared.

\subsection{Photocatalytic performance}

The photocatalytic activity of $\mathrm{BiSl} / \mathrm{Ag}_{2} \mathrm{CO}_{3}$ was evaluated by degradation of $\mathrm{RhB}$ under visible light. For comparison, the photocatalytic properties of $\mathrm{BiSI}$ and $\mathrm{Ag}_{2} \mathrm{CO}_{3}$ photocatalysts were also presented under identical experimental conditions. As shown in Fig. $6 \mathrm{a}$, where $\mathrm{C}_{t}$ is the concentration of RhB at times $\mathrm{t}$, and $\mathrm{C}_{0}$ is the initial concentration of $\mathrm{RhB}$. During the adsorption/desorption equilibrium period of $30 \mathrm{~min}$ in dark, the degradation of $\mathrm{RhB}$ was slower for $\mathrm{Ag}_{2} \mathrm{CO}_{3}$ and $\mathrm{BiSl} / \mathrm{Ag}_{2} \mathrm{CO}_{3}$, and $\mathrm{BiSl}$ shows the best adsorption capacity for RhB. During the light period, BiSI has almost no degradation effect on $\mathrm{RhB}$, and $\mathrm{Ag}_{2} \mathrm{CO}_{3}$ has poor degradation effect on RhB.. After the introduction of BiSl, the photocatalytic performance has been significantly improved. The content of BiSI will affect the photocatalytic activity of the composite photocatalyst, so we compared $\mathrm{BiSI} / \mathrm{Ag}_{2} \mathrm{CO}_{3}$ composite photocatalysts with different mass percentages to degrade RhB. Clearly, the best content of $\mathrm{BiSI}$ is $40 \%$. After 45 min of irradiation, the degradation rate of $\mathrm{RhB}$ reaches $99.6 \%$. However, with further increase in BiSI content, a small decrease in photocatalytic activity appears.

The photocatalytic degradation process can be expressed as the pseudo-first order model by the equation $-\ln \left(C_{t} / C_{0}\right)=k t$. Where $k$ is the pseudo-first order rate constant. The photocatalytic performance of the sample can also be evaluated by the reaction rate constant $k$ value. The greater the $k$ value, the better the photocatalytic performance of the product. The kinetic plots of different samples are shown in Fig. $6 \mathrm{~b}$. The results show that the rate constant of $\mathrm{BiSI}$ and $\mathrm{Ag}_{2} \mathrm{CO}_{3}$ are 0.01484 and 0.00242 min-1, respectively. Significantly, the reaction rate constant of $40 \% \mathrm{BiSI} / \mathrm{Ag}_{2} \mathrm{CO}_{3}$ is $0.09797 \mathrm{~min}-1$, which is nine times that of $20 \% \mathrm{BiSl} / \mathrm{Ag}_{2} \mathrm{CO}_{3}$ and seven times that of $40 \% \mathrm{BiSl} / \mathrm{Ag}_{2} \mathrm{CO}_{3}$. Therefore, proper loading is beneficial to improve the photocatalytic effectiveness of $\mathrm{BiSl} / \mathrm{Ag}_{2} \mathrm{CO}_{3}$ composites.

Fig .5. (a) Photocatalytic degradation efficiencies of RhB under visible light irradiation; (b) the pseudo-first order rate constants of RhB photodegradation over different photocatalysts.

\subsection{Mechanism of photocatalytic enhancement}

In order to better propose the catalytic mechanism of the $\mathrm{BiSI} / \mathrm{Ag}_{2} \mathrm{CO}_{3}$ composite photocatalyst, the semiconductor type and flat band potentials of $\mathrm{BiSI}$ and $\mathrm{Ag}_{2} \mathrm{CO}$ were studied by using an electrochemical workstation, as shown in the Mott-Schottky (M-S) curve in Figure 6. It can be seen from Fig. $6 \mathrm{a}$ and $6 \mathrm{~b}$ that the slope of the M-S curve of BiSI and $\mathrm{Ag}_{2} \mathrm{CO}_{3}$ is a positive value, so BiSI and $\mathrm{Ag}_{2} \mathrm{CO}_{3}$ are $n$-type 
semiconductors. And from the intercept results, it can be obtained that the flat band potential of BiSI is $-0.27 \mathrm{eV}$ (vs. saturated calomel electrode (SCE)) and the flat band potential of $\mathrm{Ag}_{2} \mathrm{CO}_{3}$ is $0.28 \mathrm{eV}$ (vs. SCE). From the standard hydrogen electrode $(\mathrm{NHE})=\mathrm{SCE}+0.24 \mathrm{eV}$, the flat band potentials of $\mathrm{BiSI}$ and $\mathrm{Ag}_{2} \mathrm{CO}_{3}$ are equal to $-0.03 \mathrm{eV}$ (vs. NHE) and $0.52 \mathrm{eV}$ (vs. NHE), respectively. Generally, the conduction band potential of an n-type semiconductors is $0.1 \mathrm{eV}$ lower than the flat band potential ${ }^{[31]}$. Therefore, the $\mathrm{CB}$ value of $\mathrm{BiSI}$ and $\mathrm{Ag}_{2} \mathrm{CO}_{3}$ can be estimated to be $-0.13 \mathrm{eV}$ and $0.42 \mathrm{eV}$ (vs. NHE), respectively. According to the formula $\mathrm{E}_{\mathrm{VB}}=\mathrm{E}_{\mathrm{CB}}+\mathrm{Eg}$, The $\mathrm{VB}$ and $\mathrm{CB}$ of $\mathrm{BiSI}$ and $\mathrm{Ag}_{2} \mathrm{CO}_{3}$ were calculated to be $1.25 \mathrm{eV}$ and 2.98 $\mathrm{eV}$, respectively.

Based on the above experimental results and theoretical analysis, we propose a mechanism diagram of the $\mathrm{BiSl} / \mathrm{Ag}_{2} \mathrm{CO}_{3}$ composite photocatalyst system promoting the degradation of $\mathrm{RhB}$, as shown in Figure 8. The valence band and conduction band of $\mathrm{BiSI}$ are higher than those of $\mathrm{Ag}_{2} \mathrm{CO}_{3}$. The conduction band of $\mathrm{BiSl}$ is between the conduction band and valence band of $\mathrm{Ag}_{2} \mathrm{CO}_{3}$ and is closer to the valence band of $\mathrm{Ag}_{2} \mathrm{CO}_{3}$. Therefore, the $\mathrm{BiSI} / \mathrm{Ag}_{2} \mathrm{CO}_{3}$ composite photocatalyst can constitute a Z-type photocatalyst system. Under the irradiation of visible light, both $\mathrm{BiSI}$ and $\mathrm{Ag}_{2} \mathrm{CO}_{3}$ were excited to generate electrons $\left(\mathrm{e}^{-}\right)$ and holes $\left(h^{+}\right)$. Due to the interaction between the interfaces, an internal electric field is formed. Under the action of the electric field, the $\mathrm{e}^{-}$in the conduction band of $\mathrm{Ag}_{2} \mathrm{CO}_{3}$ will interact with the $\mathrm{h}^{+}$in the valence band of BiSl, thereby being reorganized and consumed. Therefore, the main participants in the photocatalytic reaction are $\mathrm{e}^{-}$in the conduction band of $\mathrm{BiSI}$ and $\mathrm{h}^{+}$in the valence band of $\mathrm{Ag}_{2} \mathrm{CO}_{3}$. Since the conduction band potential of $\mathrm{BiSI}(-0.13 \mathrm{eV})$ is more negative than the potential of $\mathrm{O}_{2} /(-0.33 \mathrm{eV})$, it

could not reduce $\mathrm{O}_{2}$ to ${ }^{[31]}$; and the valence band potential of $\mathrm{Ag}_{2} \mathrm{CO}_{3}(2.98 \mathrm{eV})$ is more negative than the potential of $\mathrm{OH}^{-} / \cdot \mathrm{OH}(2.3 \mathrm{eV})$, it could reduce $\mathrm{OH}^{-}$to $\cdot \mathrm{OH}$. Therefore, for the $\mathrm{BiSI} / \mathrm{Ag}_{2} \mathrm{CO}_{3}$ composite system, the main active species that degrade $\mathrm{RhB}$ are $\mathrm{h}^{+}$(accounting for the majority) and $\cdot \mathrm{OH}$ (accounting for a small part).

\section{Conclusion}

In this work, a series of $\mathrm{BiSI} / \mathrm{Ag}_{2} \mathrm{CO}_{3}$ composite photocatalysts with different mass fractions were successfully prepared. The series of characterization results show that the addition of BiSI expands the responsive wavelength and enhancing the absorption intensity, reduces the migration resistance of photo-generated carriers, promotes the separation and utilization of photo-generated carriers, and thus improves the photocatalytic activity of $\mathrm{Ag}_{2} \mathrm{CO}_{3}$. The photocatalytic activity of the samples was evaluated by photocatalytic degradation of $\mathrm{RhB}$ under the irradiation of visible light. The results showed that when the mass fraction of $\mathrm{BiSI}$ is $40 \%$, the $\mathrm{BiSI} / \mathrm{Ag}_{2} \mathrm{CO}_{3}$ composites have the highest photocatalytic degradation rate, and the degradation rate of $\mathrm{RhB}$ can reach $99.6 \%$ in 45 minutes. Additionally, the VB and $\mathrm{CB}$ values of $\mathrm{BiSI}$ and $\mathrm{Ag}_{2} \mathrm{CO}_{3}$ are inferred from the $\mathrm{M}-\mathrm{S}$ curve, and a reasonable photocatalytic mechanism was proposed. Photocatalytic mechanism investigations demonstrated that the photogenerated $\mathrm{h}^{+}$and $\cdot \mathrm{OH}$ played a key role in the photocatalytic process of the $\mathrm{BiSI} / \mathrm{Ag}_{2} \mathrm{CO}_{3}$ composite 
photocatalysts under the irradiation of visible light. This work is expected to be applied to the treatment of organic pollutants in wastewater in the future and provide new ideas.

\section{References}

1. X. Hui, Y. Xu, H. Li et al., Synthesis, characterization and photocatalytic property of $\mathrm{AgBr} / \mathrm{BiPO}_{4}$ heterojunction photocatalyst[J]. Dalton Trans. 41(12), 3387-3394 (2012)

2. S. Liu, J. Yu, M. Jaroniec, Tunable Photocatalytic Selectivity of Hollow $\mathrm{TiO}_{2}$ Microspheres Composed of Anatase Polyhedra With Exposed \{001 Facets[J]. J. Am. Chem. Soc. 132(34), 11914-11916 (2010)

3. X. Zhong, L.H. Yang, X. Qu et al., Crystal Structures and Electronic Properties of Oxygen-rich Titanium Oxides at High Pressure[J]. Inorg. Chem. 157(6), 3254-3260 (2018)

4. Z.Y. Liu, Q.Y. Wang, X.Y. Tan et al., Enhanced photocatalytic performance of $\mathrm{TiO}_{2} \mathrm{NT}$ s decorated with chrysanthemum-like BiOI nanoflowers[J], 215 (Separation \& Purification Technology, 2019), pp. 565572

5. W. Zhou, C. Yu, Q. Fan et al., Ultrasonic fabrication of $\mathrm{N}$-doped $\mathrm{TiO}_{2}$ nanocrystals with mesoporous structure and enhanced visible light photocatalytic activity[J]. Chin. J. Catal. 34(6), 1250-1255 (2013)

6. Z.P. Xing, J.Q. Zhang, J.Y. Cui et al. Recent advances in floating $\mathrm{TiO}_{2}$-based photocatalysts for environmental application[J]. Applied Catalysis, B. Environmental: An International Journal Devoted to Catalytic Science and Its Applications, 2018, 225: 452-467

7. J.D. Hu, H. Xu, S.Q. Wang et al., In-situ solid-state synthesis and regulation of $\mathrm{Ag}_{2} \mathrm{O} / \mathrm{Ag}_{2} \mathrm{CO}_{3}$ heterojunctions with promoted visible-light driven photocatalytic decomposition for organic pollutant[J]. Separation \& Purification Technology 226, 95-108 (2019)

8. Y. Ao, L. Xu, P. Wang et al., Graphene and $\mathrm{TiO}_{2}$ co-modified flower-like $\mathrm{Bi}_{2} \mathrm{O}_{2} \mathrm{CO}_{3}$ : A novel multiheterojunction photocatalyst with enhanced photocatalytic activity[J]. Appl. Surf. Sci. 355, 411-418 (2015)

9. A. Phuruangrat, T. Oncharoen, N. Ekthammathat et al., Synthesis and Characterization of $\mathrm{AgCl} / \mathrm{ZnO}$ Nanocomposites for High Efficiency Photodegradation of Methylene Blue[J]. Russ. J. Phys. Chem. A 93(2), 319-323 (2019)

10. H. Hao, X. Yi, Z. Zhao et al., Gram-scale wet chemical synthesis of $\mathrm{Ag}_{2} \mathrm{O} / \mathrm{TiO}_{2}$ aggregated sphere heterostructure with high photocatalytic activity[J]. Mater. Lett. 91, 81-83 (2013)

11. Q. Zhu, W.S. Wang et al., Facile Synthesis of the Novel $\mathrm{Ag}_{3} \mathrm{VO}_{4} / \mathrm{AgBr} / \mathrm{Ag}$ Plasmonic Photocatalyst with Enhanced Photocatalytic Activity and Stability[J]. J. Phys. Chem. B 117(1), 5894-5900 (2013)

12. J. Guo, H. Shi, X. Huang et al., $\mathrm{AgCl} / \mathrm{Ag}_{3} \mathrm{PO}_{4}$ : A Stable Ag-Based Nanocomposite Photocatalyst with Enhanced Photocatalytic Activity for the Degradation of Parabens[J]. J. Colloid Interface Sci. 515, 
10-17 (2018)

13. C. Tang, Li et al., Efficient photocatalytic degradation of organic dyes and reaction mechanism with $\mathrm{Ag}_{2} \mathrm{CO}_{3} / \mathrm{Bi}_{2} \mathrm{O}_{2} \mathrm{CO}_{3}$ photocatalyst under visible light irradiation[J]. Journal of Molecular Catalysis $\mathrm{A}$ Chemical 425, 124-135 (2016)

14. J.D. Li, L.F. Wei et al., Preparation and characterization of graphene oxide/ $/ \mathrm{Ag}_{2} \mathrm{CO}_{3}$ photocatalyst and its visible light photocatalytic activity[J]. Appl. Surf. Sci. 358, 168-174 (2015)

15. D. Xu, B. Cheng, J. Zhang et al., Photocatalytic activity of $\mathrm{Ag}_{2} \mathrm{MO}_{4}(\mathrm{M}=\mathrm{Cr}, \mathrm{Mo}, \mathrm{W})$ photocatalysts[J]. Journal of Materials Chemistry A 3(40), 20153-20166 (2015)

16. W. Wang, Y. Liu, H. Zhang et al., Re-investigation on reduced graphene oxide/ $\mathrm{Ag}_{2} \mathrm{CO}_{3}$ composite photocatalyst: An insight into the double-edged sword role of RGO[J]. Appl. Surf. Sci. 396, 102-109 (2017)

17. W.J. An, K.L. Sun et al., The Z-scheme $\mathrm{Ag}_{2} \mathrm{CO}_{3} @ g-\mathrm{C}_{3} \mathrm{~N}_{4}$ core-shell structure for increased photoinduced charge separation and stable photocatalytic degradation - ScienceDirect[J]. Appl. Surf. Sci. 504, 144345 (2020)

18. N. Wang, L. Shi, L.Z. Yao et al., Highly improved visible-light-induced photocatalytic performance over $\mathrm{BiOl} / \mathrm{Ag}_{2} \mathrm{CO}_{3}$ heterojunctions[J]. RSC Advances 8(1), 537-546 (2017)

19. S. Lei, L. Lin, F. Wang et al., $\mathrm{Ag}_{2} \mathrm{CrO}_{4}$ nanoparticles loaded on two-dimensional large surface area graphite-like carbon nitride sheets: simple synthesis and excellent photocatalytic performance[J]. Dalton Trans. 45(13), 5815 (2016)

20. K.H. Reddy, S. Martha, K.M. Parida, Fabrication of Novel p-BiOl/n-ZnTiO ${ }_{3}$ Heterojunction for Degradation of Rhodamine 6G under Visible Light Irradiation[J]. Inorg. Chem. 52(11), 6390-6401 (2013)

21. J.F. Chen, J.B. Zhong, J.Z. Li et al., Synthesis and characterization of novel $\mathrm{Ag}_{2} \mathrm{CO}_{3} / \mathrm{g}-\mathrm{C}_{3} \mathrm{~N}_{4}$ composite photocatalysts with excellent solar photocatalytic activity and mechanism insight[J]. Molecular Catalysis 435, 91-98 (2017)

22. N. Tian, H.W. Huang, Y. He et al., Organic-inorganic hybrid photocatalyst g- $\mathrm{C}_{3} \mathrm{~N}_{4} / \mathrm{Ag}_{2} \mathrm{CO}_{3}$ with highly efficient visible-light-active photocatalytic activity[J]. Colloids Surf. A: Physicochem. Eng. Aspects 467, 188-194 (2015)

23. H.Y. Liu, C. Liang, C.G. Niu et al., Facile assembly of g- $\mathrm{C}_{3} \mathrm{~N}_{4} / \mathrm{Ag}_{2} \mathrm{CO}_{3} /$ graphene oxide with a novel dual Zscheme system for enhanced photocatalytic pollutant degradation[J]. Appl. Surf. Sci. 475, 421-434 (2019)

24. S. Tonda, S. Kumar, V. Shanker, In situ growth strategy for highly efficient $\mathrm{Ag}_{2} \mathrm{CO}_{3} / g-\mathrm{C}_{3} \mathrm{~N}_{4}$ hetero/nanojunctions with enhanced photocatalytic activity under sunlight irradiation[J]. Journal of Environmental Chemical Engineering 3(2), 852-861 (2015)

25. H.B. Sun, P.F. Qin, Z.B. Wu et al., Visible light-driven photocatalytic degradation of organic pollutants by a novel $\mathrm{Ag}_{3} \mathrm{VO}_{4} / \mathrm{Ag}_{2} \mathrm{CO}_{3}$ pen heterojunction photocatalyst: Mechanistic insight and degradation pathways[J]. J. Alloy. Compd. 834, 155211-155217 (2020) 
26. $\mathrm{H}$. Xu, Y. Song et al., Synthesis and characterization of $\mathrm{g}-\mathrm{C}_{3} \mathrm{~N}_{4} / \mathrm{Ag}_{2} \mathrm{CO}_{3}$ with enhanced visible-light photocatalytic activity for the degradation of organic pollutants[J]. RSC Advances 4(65), 3453934547 (2014)

27. X. Wu, Y. Hu, Y. Wang et al., In-situ synthesis of Z-scheme $\mathrm{Ag}_{2} \mathrm{CO}_{3} / \mathrm{Ag} / \mathrm{AgNCO}$ heterojunction photocatalyst with enhanced stability and photocatalytic activity[J]. Appl. Surf. Sci. 464, 108-114 (2018)

28. C. Zhou, R. Wang, C. Jiang et al. Dynamically Optimized Multi-Interface Novel BiSI-Promoted Redox Sites Spatially Separated N-p-n Double Heterojunctions BiSI/MoS $2 / C d S$ for Hydrogen Evolution[J]. Industrial \& Engineering Chemistry Research, 2019, 58(19): pp. 7844-7856

29. J. Li, R. Guan, J. Zhang et al., Preparation and Photocatalytic Performance of Dumbbell $\mathrm{Ag}_{2} \mathrm{CO}_{3}-\mathrm{ZnO}$ Heterojunctions[J]. ACS Omega 5(1), 570-577 (2019)

30. J. Ran, Y.M. Tian, G. Gao et al., Porous P-doped graphitic carbon nitride nanosheets for synergistically enhanced visible-light photocatalytic $\mathrm{H}_{2}$ production[J]. Energy Environ. Sci. 8(12), 3708-3717 (2015)

31. J.L. Wang, Y. Yu, L.Z. Zhang, Highly efficient photocatalytic removal of sodium

32. pentachlorophenate with, Bi304Br under visible light[J]. Appl. Catal. B 136, 113-121 (2013)

33. B.M. Pirzada, R.K. Pushpendra, Kunchala et al., Synthesis of $\mathrm{LaFeO}_{3} / \mathrm{Ag}_{2} \mathrm{CO}_{3}$ Nanocomposites for Photocatalytic Degradation of Rhodamine B and p -Chlorophenol under Natural Sunlight[J]. ACS Omega 4(2), 2618-2629 (2019)

\section{Figures}




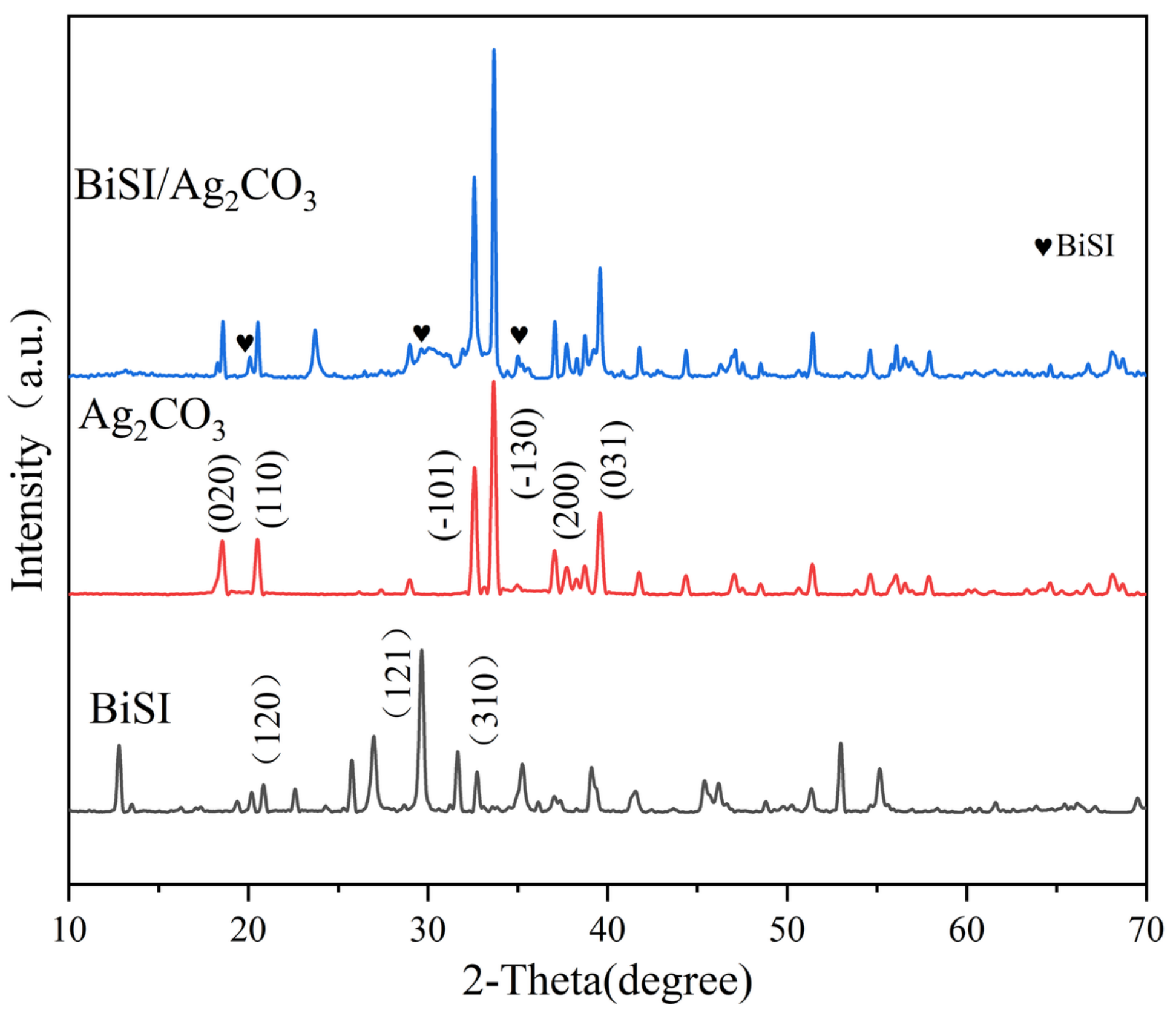

Figure 1

XRD pattern of $\mathrm{BiSl}, \mathrm{Ag} 2 \mathrm{CO} 3$ and $\mathrm{BiSl} / \mathrm{Ag} 2 \mathrm{CO} 3$.

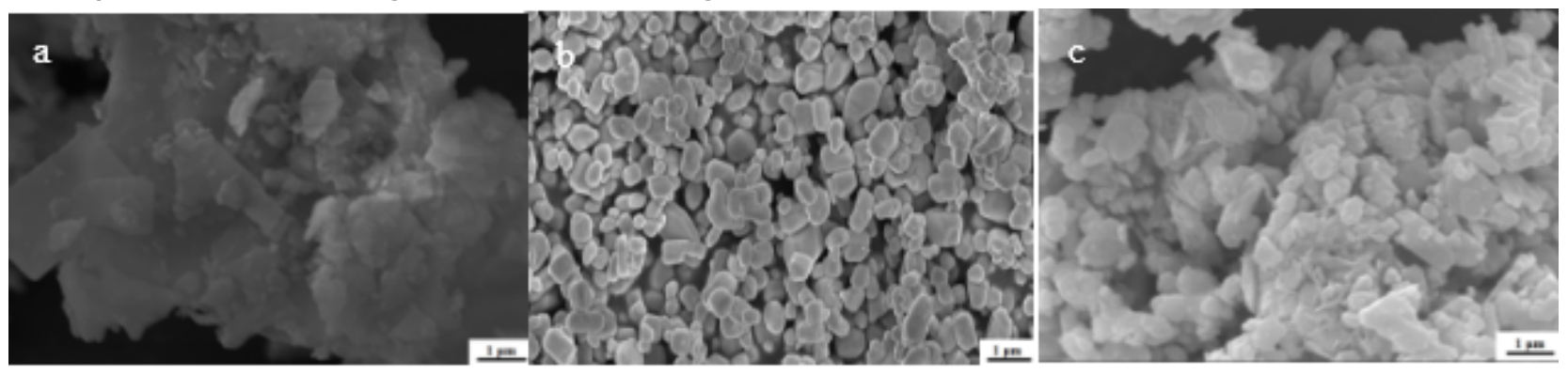

Figure 2

SEM image of (a) BiSl, (b) Ag2CO3, (c) BiSI/Ag2CO3. 

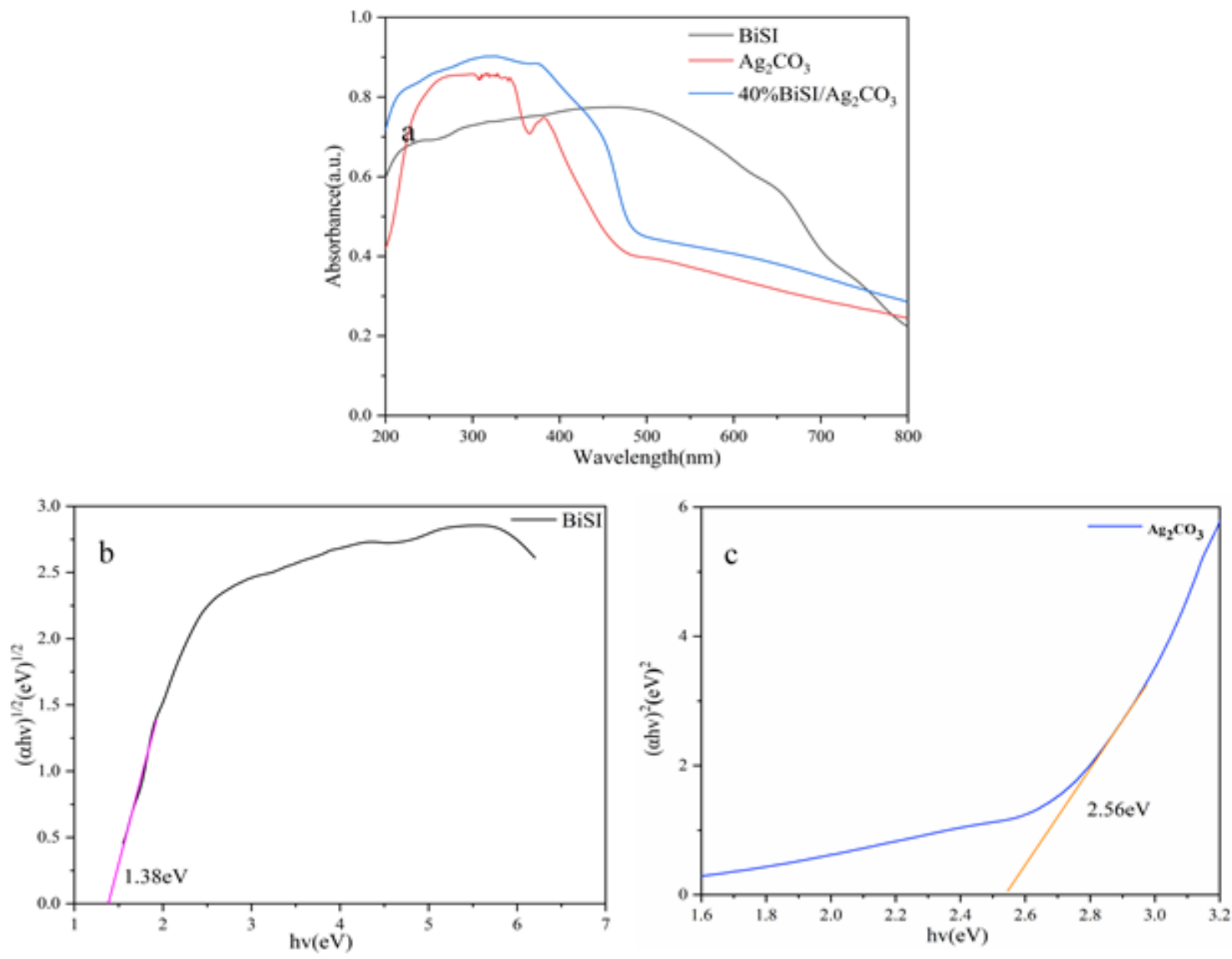

Figure 3

(a) UV-vis diffuse reflflectance spectra of BiSI, Ag2 $\mathrm{CO} 3$ and BiSI/Ag2CO3; The band gap energies of BiSI (b) and $\mathrm{Ag} 2 \mathrm{CO} 3(\mathrm{c})$ 

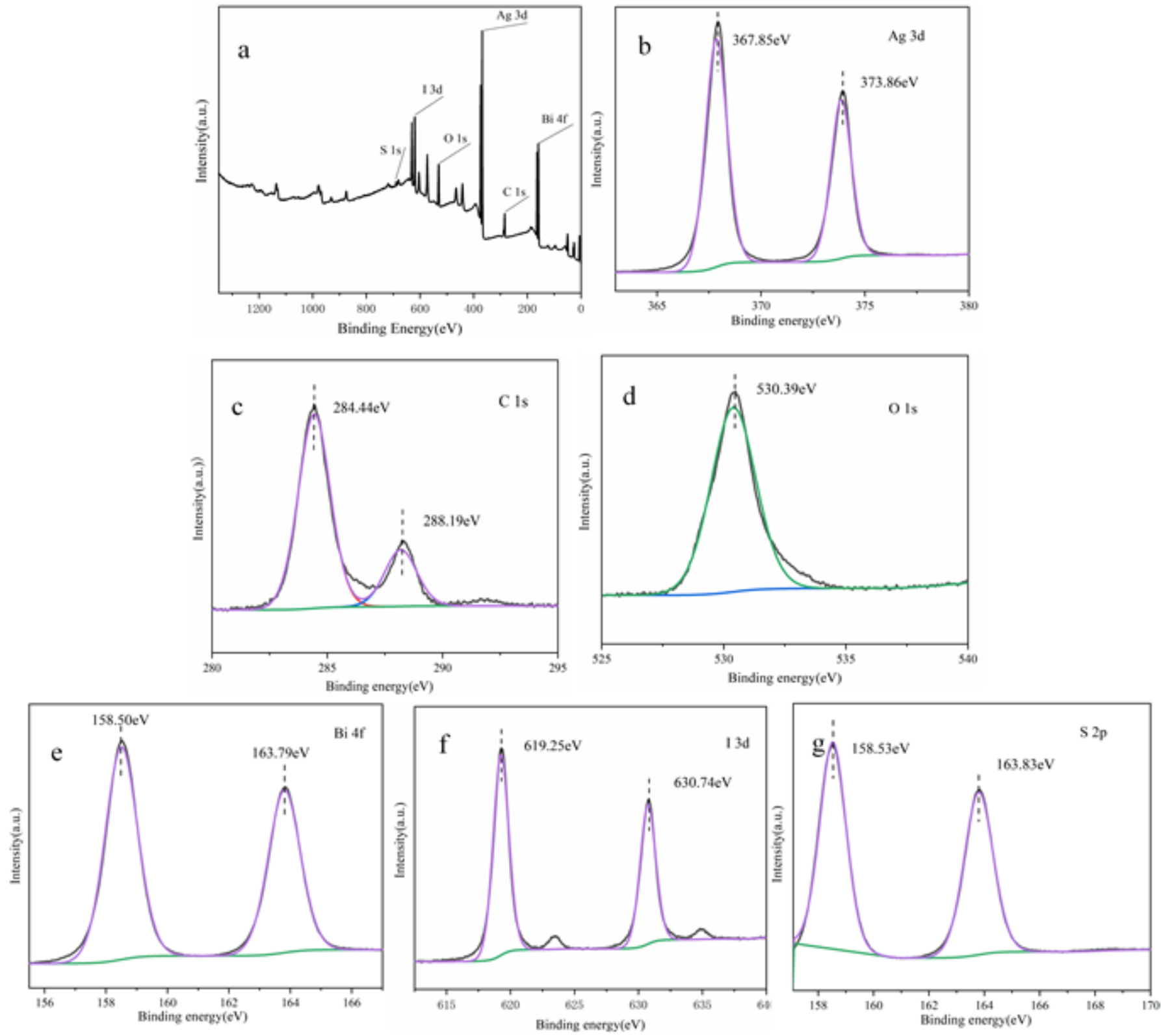

Figure 4

XPS spectrum of the BiSI/Ag2CO3: (a) survey spectrum; (b) Ag 3d; (c) C 1s; (d) 0 1s; (e) Bi 4f; (f) I 3d and (g) $S 2 p$. 


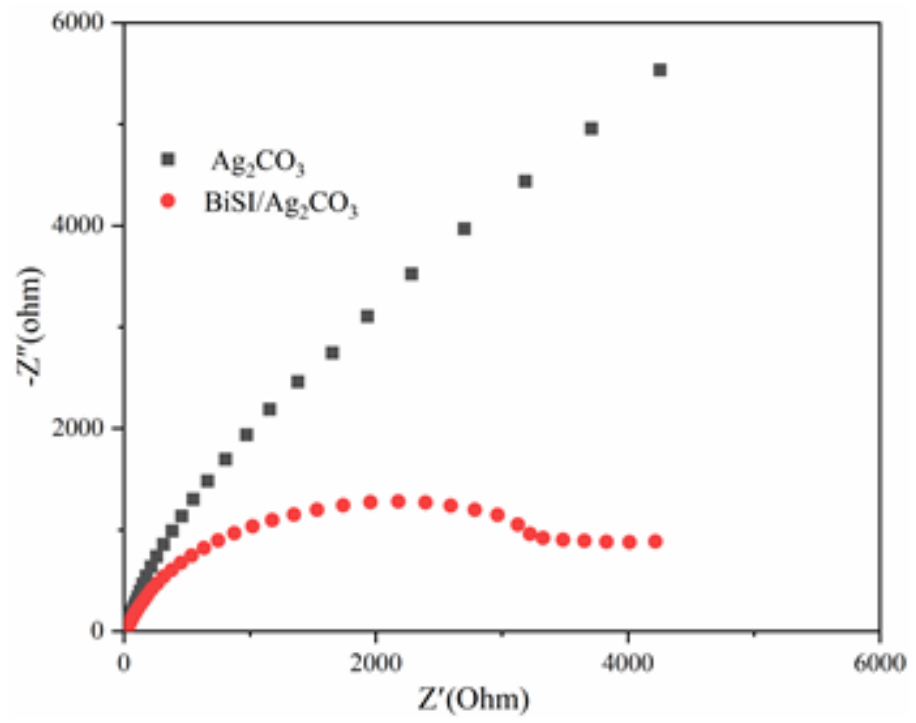

Figure 5

EIS Nyquist plot of the sample
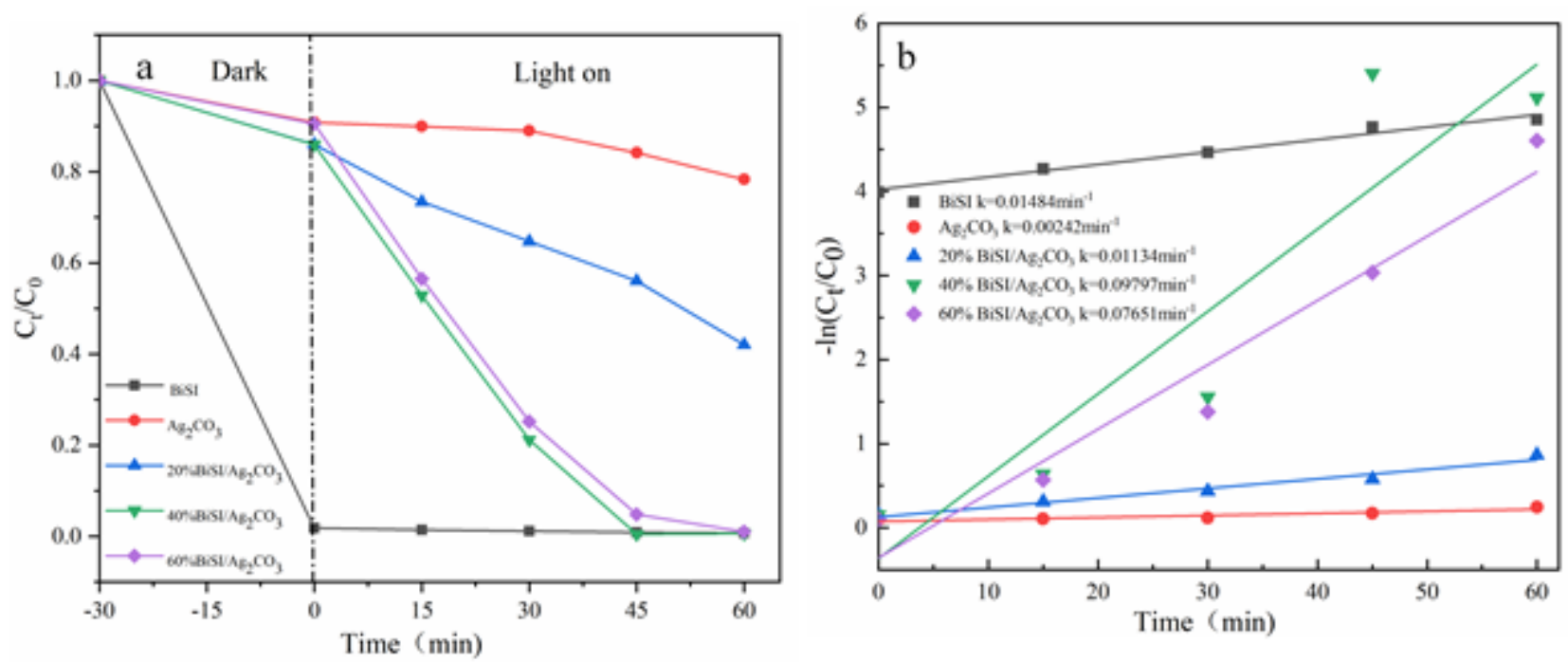

Figure 6

(a) Photocatalytic degradation efficiencies of RhB under visible light irradiation; (b) the pseudo-first order rate constants of $\mathrm{RhB}$ photodegradation over different photocatalysts. 

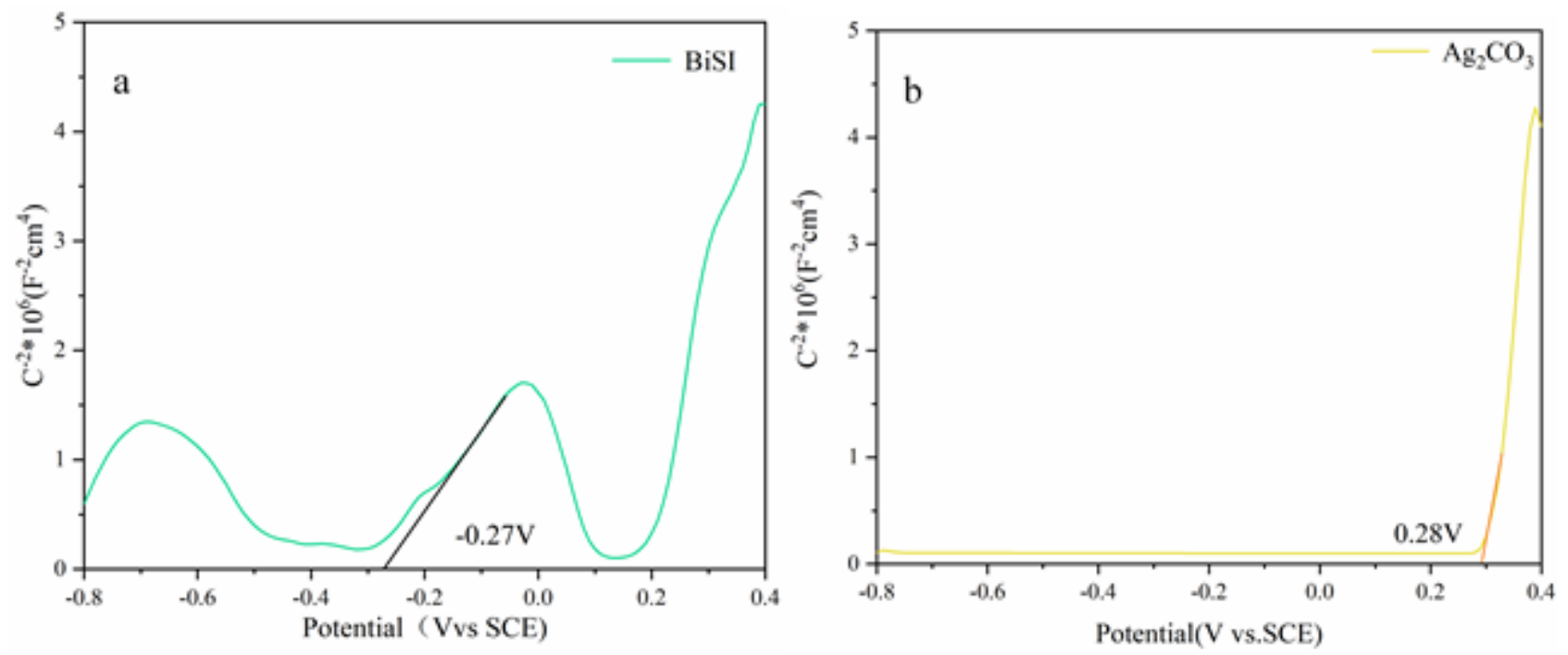

Figure 7

Mott-Schottky curves of (a) BiSI and (b) Ag2CO3

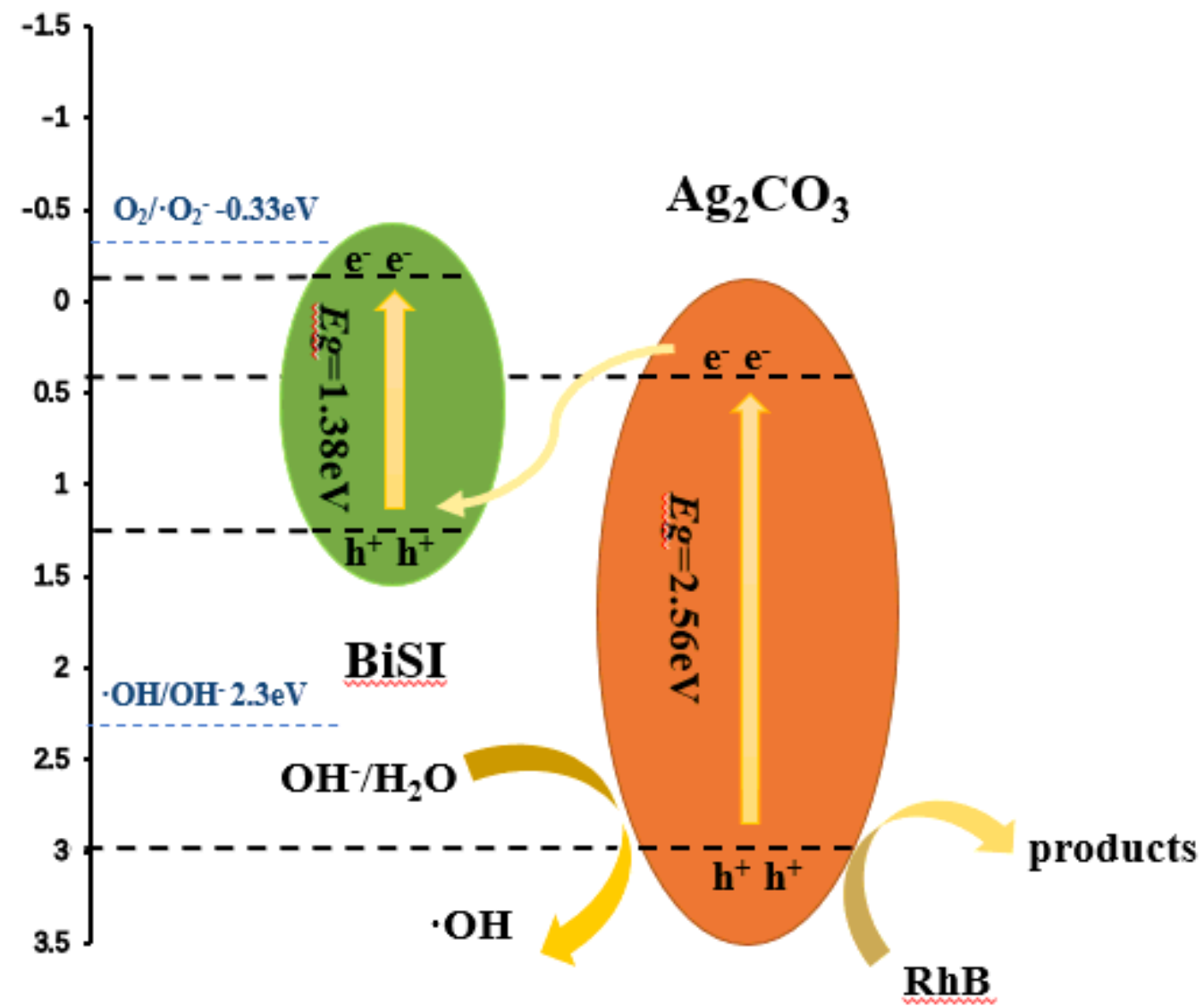

Figure 8

Proposed degradation mechanism of RhB over the BiSI/Ag2CO3 composite. 